weakness are both associated, independently of other influences, with an increased risk of hip fracture in elderly people. This points to the importance of maintaining physical activity in the day to day lives of old people.

We thank the consultants and staff of the department of orthopaedic surgery, Southampton General Hospital, and the general practitioners of the Southampton health district; $\mathrm{Mrs}$ $M$ Mitchell and Mrs S Underwood interviewed some of the patients; Mr G Butcher helped in selecting controls; Dr E J Bassey and Dr H Dallosso of the department of physiology and pharmacology, University of Nottingham Medical School, helped with the method of assessing physical activity; and Dr W J Boyce, Northampton health district, advised on the design of the study.

1 Cooper C, Barker DJP, Morris J, Briggs RSJ. Osteoporosis, falls, and age in fracture of the proximal femur. Br Med F 1987;295:13-5.

2 Anonymous. Consensus Development Conference: prophylaxis and treatment of osteoporosis. Br Med J 1987;295:914-5.

3 Kelsey JL, Hoffman S. Risk factors for hip fracture. $N$ Engl $\mathcal{f}$ Med 1987;316:404-6.

4 Quereshi KN, Hodkinson HM. Evaluation of a ten question mental test in the institutionalised elderly. Age Ageing 1974;3:152-7.

5 Dallosso HM, Morgan K, Bassey EJ, Fentem PH, Arie TDH. Levels of customary physical activity among the old and very old living at home. I E pidemiol Community Health 1988;42:121-7.

6 Department of Health and Social Security. A nutrition survey of the elderly. London: HMSO, 1972. (Report on health and social subjects No 3.)
7 Nelson M, Hague GF, Cooper C, Bunker VW. Calcium intake in the elderly validation of a dietary questionnaire. Joumal of Human Nutrition and Dietetics 1988;1:115-27.

8 Breslow NE, Day NE. Conditional logistic regression for matched sets. In: Breslow NE, Day NE, eds. Statistical methods in cancer research. Volume 1 . The analysis of case control studies. Lyons: International Agency Research on The analysis of case con

9 Krolner B, Toft B. Vertebral bone loss: an unheeded side effect of therapeutic bed rest. Clin Sci 1983;64:537-40.

10 Mack PB, LaChance PA, Vose GP, Vogt FB. Bone demineralisation of foo and hand of Gemini-Titan IV, V and VII astronauts during orbital flights. American fournal of Roentgenology, Radium Therapy and Nuclear Medicin 1967;100:503-11

11 Huddleston AL, Rockwell D, Kulund DN, Harrison RB. Bone mass in lifetime tennis athletes. FAMA 1980;244:1107-9.

12 Chow R, Harrison JE, Notarius CE. Effect of two randomised exercise programmes on bone mass of healthy postmenopausal women. $\mathrm{Br} \mathrm{Med} \mathcal{F}$ 1987;295:1441-4.

13 Wickham C, Cooper C, Margetts BM, Barker DJP. Muscle strength, activity, housing and the risk of falls in the elderly. Age Ageing (in press.)

14 Matkovic V, Kostial K, Simonivoc I, Buzina R, Brodarec A, Nordin BEC. Bone status and fracture rates in two regions of Yugoslavia. Am $\mathcal{f}$ Clin Nutr 1979;32:540-9.

15 Baker MR. The epidemiology and aetiology of femoral neck fracture. Newcastle upon Tyne: University of Newcastle upon Tyne, 1980. (MD Dissertation.) 16 Wootton R, Brereton PJ, Clark MB, Hesp R, Hodkinson HM, Klenerman L. Fractured neck of femur in the elderly: an attempt to identify patients a risk. Clin Sci 1979;57:93-101.

17 Heaney RP, Recker RR, Saville PD. Menopausal changes in calcium balance performance. F Lab Clin Med 1978;92:953-64

18 Horsman A, Gallagher JC, Simpson M, Nordin BEC. Prospective trial of oestrogen and calcium in postmenopausal women. $\mathrm{Br}$ Med $\mathrm{f}$ 1977;ii:789-92.

19 Riis B, Thomsen K, Christiansen C. Does calcium supplementation prevent postmenopausal bone loss? A double blind, controlled clinical study. $N \mathrm{Engl}$ f Med 1987;316:173-7.

(Accepted 20 September 1988)

\section{Effects of withdrawal of co-danthramer on use of laxatives in a district general hospital}

\author{
D R Upton, J K Taylor, G K T Holmes, \\ J W Poston
}

\section{Medicines Research Unit, District Pharmacy, Derbyshire Royal \\ Infirmary, Derby DE1 2QY \\ D R Upton, MRPHARMS, staff} pharmacist

J K Taylor, MRPHARMS, resident pharmacist

G K T Holmes, FRCP, consultant physician

Welsh School of Pharmacy, University of Wales Institute of Science and Technology, Cardiff CF1 3NU

$\mathrm{J}$ W Poston, PHD, associate director

Correspondence to: $\mathrm{Mr}$ Upton.
In March 1987, after new evidence that long term administration of high doses of danthron was associated with tumours in rodents, the manufacturers of co-danthramer (Dorbanex and Dorbanex Forte) surrendered product licences for these preparations. ${ }^{1}$ At this hospital co-danthramer was used extensively as a result of routine prescribing and a policy permitting nursing staff to administer up to three doses of the liquid laxative without a prescription, a ruling also applied to senna tablets. After the withdrawal the drugs and therapeutics subcommittee issued guidance that treatment of constipation should be based on dietary or prescribed fibre, though if a stimulant laxative was necessary senna provided a suitable alternative to co-danthramer. Senna syrup replaced co-danthramer as the liquid laxative to be given by nurses. Lactulose was discouraged as a first line laxative, being unsuitable for administration as required and fairly expensive. This guidance was supplemented by a bulletin from the district drug information centre.

We looked at use of laxatives before and after the withdrawal of co-danthramer and assessed changes in view of the recommendations made.

\section{Method and results}

Use of laxatives by inpatients was measured from data on the pharmacy computer on issues to the wards. This information was converted to defined daily doses, a unit defined as the assumed average daily dose of the drug when used for its main indication in adults. ${ }^{2}$ The values used were determined after consultation with colleagues. To relate defined daily dose to patient numbers we determined the number of occupied bed days recorded for the hospital and then calculated the number of defined daily doses used per 100 occupied bed days. ${ }^{34}$ Use of laxatives was compared for two periods of six months (April to September) in 1986 and 1987, one before and the other after the withdrawal of co-danthramer. Financial data were also considered to assess the implications in terms of cost of changing patterns of use of laxatives.

The results confirmed that co-danthramer liquid was the most used laxative preparation in 1986 (at 10.9 defined daily doses per 100 occupied bed days), accounting for $37 \%$ of all laxative use, with lactulose and ispaghula sachets ranked second and third (table).

Use of laxatives from April to September, 1986 and 1987. Values are expressed as defined daily doses per 100 occupied bed days

\begin{tabular}{lrr}
\hline Laxative & 1986 & 1987 \\
\hline Co-danthramer liquid & $10 \cdot 9$ & \\
Lactulose & $6 \cdot 4$ & 10.9 \\
Ispaghula sachets & $5 \cdot 5$ & $4 \cdot 4$ \\
Glycerin suppositories & $2 \cdot 2$ & $2 \cdot 4$ \\
Senna tablets & $1 \cdot 3$ & 3.9 \\
Senna syrup & $0 \cdot 1$ & $5 \cdot 9$ \\
Phosphate enemas & $0 \cdot 7$ & $0 \cdot 8$ \\
Sodium citrate enemas & $0 \cdot 6$ & 0.9 \\
Bisacodyl suppositories & $0 \cdot 2$ & 0.6 \\
Docusate sodium 100 mg tablets & $0 \cdot 2$ & 0.7 \\
Other preparations & 0.6 & 0.3 \\
\hline
\end{tabular}

The total use of laxatives rose from $29 \cdot 3$ defined daily doses per 100 occupied bed days in 1986 to $31 \cdot 3$ in 1987, when lactulose was the most commonly used agent. The use of ispaghula fell in 1987 while use of senna preparations, particularly the syrup, showed a pronounced rise. Expenditure on laxatives rose considerably after the withdrawal of co-danthramer, from $£ 1986$ for the six months in 1986 to $£ 3274$ for the corresponding period in 1987.

\section{Comment}

The total use of laxatives increased by 7\% from 1986 to 1987 , whereas expenditure rose by $65 \%$. Even allowing for inflation and price rises, this suggests that costs increased because expensive preparations were used rather than because of a large increase in use. 
Reasons behind the changes are difficult to determine. Possibly the tendency was to replace one liquid laxative with another in the belief that liquid preparations are more effective than tablets or fibre products. Thus although the use of senna tablets increased, the rise in the use of senna syrup was much greater, partly because it was given by nursing staff.

Increased prescribing of lactulose may have been due to extensive promotion, the wish to use a liquid preparation, and the perception that the potential lack of griping was an important benefit. Recommendations made to prescribers were not followed, and we conclude that the educational bulletins issued to promote fibre as a first line laxative were not enough to influence prescribing without some form of reinforcement.

We thank Mr P D Fox, Trent Regional Computer Centre, and Dr S R Carr.

1 Anonymous. Riker stops making Dorbanex because of concern about safery. Pharmaceutical fournal 1987;238:96.

2 Nordic Council on Medicines. Nordic Statistics on Medicines 1981-3. Uppsala, Sweden: Nordic Council on Medicines, 1986.

3 Bergman U. Auditing hospital drug utilisation by means of defined daily doses per bed day. A methodological study. Eur f Clin Pharmacol 1980;17:183-7. 4 Hekster YA, Vree TB, Goris RJA, Boerema JBJ. The defined daily dose per 100 bed-days as a unit of comparison and a parameter for studying antimicrobial drug use in a university hospital. Fournal of Clinical and Hospital Pharmacy 1982;7:251-60.

(Accepted 23 August 1988)

\section{An endocrine marker for pancreatic cancer}

\section{Z Tulassay, Z Sándor, L Bodrogi, J Papp, T Fehér}

First Department of Medicine, Semmelweis University School of Medicine, 1083 Budapest, Korányi u 2/a, Hungary $\mathrm{Z}$ Tulassay, $\mathrm{MD}$, associate professor

Z Sándor, MD, research officer

L Bodrogi, research officer

J Papp, MD, associate professor

T Fehér, csc, chief medical

laboratory scientific officer

Correspondence to: Dr Tulassay.
Although the pancreas is not considered to be a target organ for steroid hormones, abnormally high serum concentrations of sex hormones have been observed in patients with pancreatic diseases. ${ }^{1-3}$ The purpose of this study was to investigate the role of androgens in pancreatic diseases and the possible diagnostic value of measuring sex hormone concentrations to differentiate between various pancreatic diseases.

\section{Patients, methods, and results}

We studied 75 men who were arranged in four groups according to their diagnoses. Group 1 consisted of 14 patients with pancreatic cancer that was confirmed histologically at operation (mean age 55). Group 2 consisted of 26 patients with chronic pancreatitis (mean age 44) with a diagnosis based on the symptoms of insufficient secretion of hormones, typical changes on ultrasonography and pancreatography, and the findings at operation. Group 3 consisted of 19 patients with malignancies of the gastrointestinal tract other than of the pancreas that were confirmed endoscopically and histologically (three oesophagus, six stomach, seven colon, and three papilla of Vater) (mean age 57). Group 4 consisted of 16 control subjects without gastrointestinal or endocrine diseases (mean age 53).

Blood samples were taken between 8 and $10 \mathrm{am}$. Testosterone, dihydrotestosterone, and androstenedione concentrations were measured by radioimmunoassay, ${ }^{4}$ and the ratio of testosterone to dihydrotestosterone was calculated.

The mean (SD) concentration of testosterone in patients with pancreatic cancer was $7 \cdot 4(1 \cdot 2) \mathrm{nmol} / \mathrm{l}$, which was lower than that in those from the other groups (group 2, $11.6(6.4) \mathrm{nmol} / \mathrm{l}$; group 3, 7.8 $(5 \cdot 3) \mathrm{nmol} / \mathrm{l}$; group $4,9.6(5 \cdot 3) \mathrm{nmol} / \mathrm{l})$. The differences, however, were not statistically significant. The mean (SD) dihydrotestosterone concentrations were $3 \cdot 2(2 \cdot 3) \mathrm{nmol} / 1,1 \cdot 5(1 \cdot 6) \mathrm{nmol} / 1,1.9(0 \cdot 9) \mathrm{nmol} / \mathrm{l}$, and $1.7(0.9) \mathrm{nmol} / 1$ for groups $1,2,3$, and 4 respectively. The corresponding androstenedione concentrations were $8 \cdot 8(2 \cdot 5) \mathrm{nmol} / \mathrm{l}, 9 \cdot 5(3 \cdot 2) \mathrm{nmol} / \mathrm{l}$, $8 \cdot 2(3 \cdot 1) \mathrm{nmol} / \mathrm{l}$, and $9 \cdot 4(5 \cdot 2) \mathrm{nmol} / \mathrm{l}$. There were no significant differences between any of the groups. The mean (SD) ratio of testosterone to dihydrotestosterone was, however, significantly lower in patients with pancreatic cancer than in those with chronic pan- creatitis $(2.5(1.0) v 9 \cdot 6(2.3) ; \mathrm{p}<0.01)$. In all patients with pancreatic cancer the ratio of testosterone to dihydrotestosterone was less than 4, while it exceeded 4 in all but one patient with chronic pancreatitis (figure). The mean ratio of testosterone to dihydrotestosterone in patients with gastrointestinal cancer other than of the pancreas and in controls was higher than that in patients with pancreatic cancer. The difference was not statistically significant.

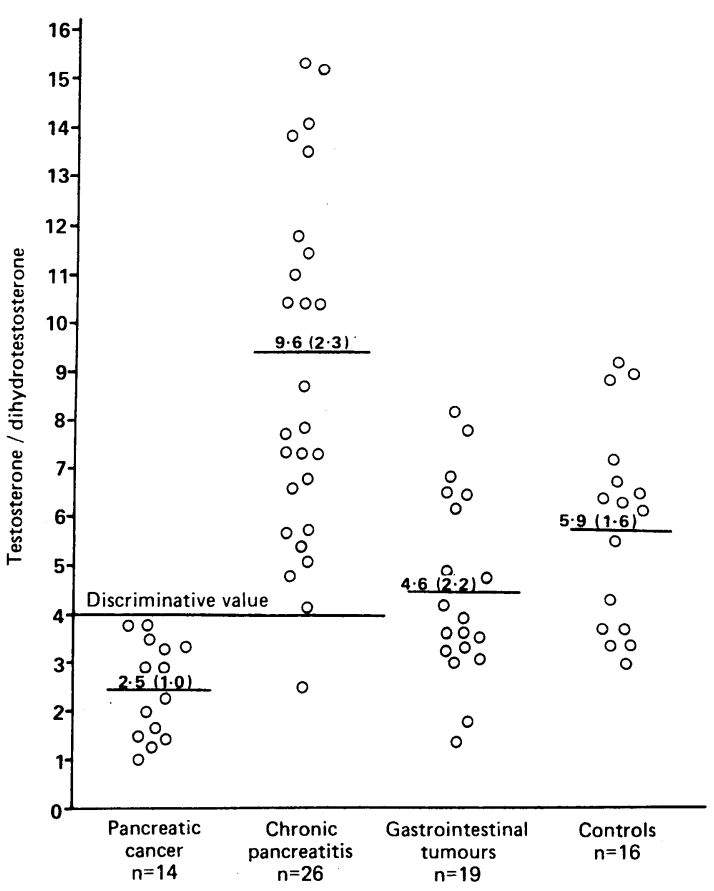

Ratio of testosterone to dihydrotestosterone in four groups of patients. Mean (SD) values for each group and the discriminative value are shown

\section{Comment}

Our results agree with the previous finding of a decrease of serum testosterone concentration in patients with pancreatic cancer. ${ }^{3}$ This finding has no diagnostic relevance because similarly low testosterone concentrations have been found in various pathological conditions. ${ }^{5}$ In this study we have shown that the ratio of testosterone to dihydrotestosterone is a valuable marker for differentiating between pancreatic cancer and chronic pancreatitis. This ratio was significantly lower in patients with pancreatic cancer than in those with chronic pancreatitis. The value which discriminated between the two groups was 4 .

The activities of aromatase and 5- $\alpha$-reductase are high in pancreatic cancer cells. ${ }^{3}$ These enzymes convert testosterone to oestrogens and dihydro- 